(C) 2020, The Authors. Published by Elsevier Inc. and Fass Inc. on behalf of the American Dairy Science Association ${ }^{\circledR}$. This is an open access article under the CC BY-NC-ND license (http://creativecommons.org/licenses/by-nc-nd/4.0/).

\title{
Multitrait genomic prediction of methane emissions in Danish Holstein cattle
}

\author{
C. I. V. Manzanilla-Pech, ${ }^{1 *}$ D. Gordo, ${ }^{1}$ G. F. Difford, ${ }^{1,2}$ P. Løvendahl, ${ }^{1}$ and J. Lassen ${ }^{3}$ \\ ${ }^{1}$ Department of Molecular Biology and Genetics, Aarhus University, PO Box 50, DK-8830 Tjele, Denmark \\ ${ }^{2}$ Department of Breeding and Genetics, Nofima AS, PO Box 210, N-1431 Ås, Norway \\ ${ }^{3}$ Viking Genetics, Ebeltoftvej 16, Assentoft, 8960 Randers, Denmark
}

\section{ABSTRACT}

In dairy cattle, selecting for lower methane-emitting animals is one of the new challenges of this decade. However, genetic selection requires a large number of animals with records to get accurate estimated breeding values (EBV). Given that $\mathrm{CH}_{4}$ records are scarce, the use of information on routinely recorded and highly correlated traits with $\mathrm{CH}_{4}$ has been suggested to increase the accuracy of genomic EBV (GEBV) through multitrait (genomic) prediction. Therefore, the objective of this study was to evaluate accuracies of prediction of GEBV for $\mathrm{CH}_{4}$ by including or omitting $\mathrm{CH}_{4}$, energy-corrected milk (ECM), and body weight (BW) as well as genotypic information in multitrait analyses across 2 methods: BLUP and single-step genomic BLUP (SSGBLUP). A total of 2,725 cows with $\mathrm{CH}_{4}$ concentration in breath $(14,125$ records), BW $(61,667$ records), and ECM (61,610 records) were included in the analyses. Approximately 2,000 of these cows were genotyped or imputed to $50 \mathrm{~K}$. Ten cross-validation groups were formed by randomly grouping paternal half-sibs. Five scenarios were performed: (1) base scenario with only $\mathrm{CH}_{4}$ information; (2) without $\mathrm{CH}_{4}$, but with information from BW, ECM, or BW+ECM only in reference population; (3) without $\mathrm{CH}_{4}$, but with information from BW, ECM, or BW+ECM in both validation and reference population; (4) with $\mathrm{CH}_{4}$ information and $\mathrm{BW}, \mathrm{ECM}$, or $\mathrm{BW}+\mathrm{ECM}$ information only in the reference population; and (5) with $\mathrm{CH}_{4}$ information and BW, ECM, or BW+ECM information in both validation and reference population. As a result, for each method (BLUP, SSGBLUP), 13 sub-scenarios were performed, 1 from scenario 1 , and 3 for each of the subsequent 4 scenarios. The average accuracy of GEBV for $\mathrm{CH}_{4}$ in the base scenario was 0.32 for BLUP and 0.42 for SSGBLUP, and it ranged from 0.10 in scenario 2 to 0.78 in scenario 5 across methods. In terms of bias, the base scenario 1 was unbiased for SSGBLUP; similar

Received November 6, 2019.

Accepted May 18, 2020.

*Corresponding author: coralia.manzanilla@mbg.au.dk results were achieved with scenario 5. Including information on ECM increased the accuracy of GEBV for $\mathrm{CH}_{4}$ by up to $61 \%$, whereas adding information on both traits (BW and ECM) increased the accuracy by up to $90 \%$. Scenarios that did not include $\mathrm{CH}_{4}$ in the reference population had the lowest correlations (0.17-0.33) with single-trait $\mathrm{CH}_{4} \mathrm{GEBV}$, and scenarios with $\mathrm{CH}_{4}$ in the reference population had the highest correlations (0.41-0.81). Thus, failure to include $\mathrm{CH}_{4}$ in future reference populations results in predicted $\mathrm{CH}_{4} \mathrm{GEBV}$, which cannot be used in practical selection. Therefore, recording $\mathrm{CH}_{4}$ in more animals remains a priority. Finally, multiple-trait genomic prediction using routinely recorded BW and ECM leads to higher prediction accuracies than traditional single-trait genomic prediction for $\mathrm{CH}_{4}$ and is a viable solution for increasing the accuracies of GEBV for scarcely recorded $\mathrm{CH}_{4}$ in practice. Key words: multitrait genomic prediction, predictor trait, methane concentration

\section{INTRODUCTION}

Methane emission of dairy cattle represents $18 \%$ of the global greenhouse gas emissions (Knapp et al., 2014). This has led to a large number of research projects investigating opportunities to reduce methane emissions in dairy cattle (de Haas et al., 2011; Waghorn and Hegarty, 2011; Garnsworthy et al., 2012; Ross et al., 2013). From the genetic point of view, methane emission has shown to be a heritable trait $(0.100 .30$; van Engelen et al., 2015; Lassen and Løvendahl, 2016; Pszczola et al., 2017; Breider et al., 2018; Difford et al., 2020), making it possible to select for lower emitting animals, with the advantage that genetic progress is cumulative and permanent. However, as $\mathrm{CH}_{4}$ is a scarcely recorded trait, it would require a considerable number of cows with $\mathrm{CH}_{4}$ records in the reference population to estimate genetic EBV (GEBV) of bulls with good accuracies (Hayes et al., 2009). At present, the accuracies of GEBV are low due to the limited number of cows with $\mathrm{CH}_{4}$ records. One approach to increase the accuracy of prediction of GEBV for $\mathrm{CH}_{4}$ given the limited amount of data available could be to in- 
clude information on routinely recorded traits that are highly genetically correlated with $\mathrm{CH}_{4}$ in a multitrait genomic prediction. Before the genomic era, Ducrocq (1994) stated the benefits from multitrait prediction in 3 points: (1) the exploitation of indirect information provided by correlated traits that is not available in selection candidates, (2) the use of additional knowledge that can increase the accuracy of the genetic evaluations, and (3) the reduction of systematic biases in the evaluations. Likewise, Ducrocq (1994) reported increases in genetic gain when the genetic correlation between traits is high when (1) the difference between the genetic and the residual correlation is large; (2) the difference in heritability is large, and the goal trait is the one with lowest heritability; and (3) more than one random effect is considered, and the full- or half-sib family size is small. More recently, it has been suggested that multiple-trait genomic selection could lead to higher prediction accuracy than single-trait genomic selection (Calus and Veerkamp, 2011; Jia and Jannink, 2012), where the magnitude of genetic correlations between the traits is the key factor determining the increase in accuracy. Within this context, BW and ECM, traits that are routinely recorded in some automated milking robots and highly correlated with $\mathrm{CH}_{4}$, could be good candidate predictor traits for $\mathrm{CH}_{4}$.

To determine the benefit of including genotypic information in the prediction of the EBV and the consistency of the predictor traits across methods, 2 methods were tested. First, BLUP used pedigree-derived additive genetic relationships to estimate an EBV for each animal in the pedigree. Second, single-step genomic BLUP (SSGBLUP; Aguilar et al., 2010; Christensen and Lund, 2010) allowed the addition of phenotypic information of non-genotyped animals into the genomic BLUP method by combining in a single step the genomic relationship matrix (GRM) with the pedigree relationship matrix into a new relationship matrix, whose inverse is used to solve the mixed-model equations to obtain the GEBV. Therefore, the objective of this study is to evaluate the accuracy of prediction and bias of GEBV for $\mathrm{CH}_{4}$ by testing a variety of scenarios with the presence or absence of predictor traits (ECM and $\mathrm{BW}$ ) and genotypes.

\section{MATERIALS AND METHODS}

\section{Phenotypes}

A total of 2,725 Danish Holstein cows with $\mathrm{CH}_{4}$ breath concentration (referred to as $\mathrm{CH}_{4} ; 14,125$ records), BW (61,667 records), and ECM (61,610 records) were available from the Danish Cattle Research Center (Foulum, Denmark; 1,328 cows) and 10 commercial farms $(1,397$ cows $)$ in Denmark. The records were collected between 2011 and 2016 as described previously in Zetouni et al. (2018) and Difford et al. (2020). Methane data (from research and commercial herds) were filtered to include only weekly averages comprising 4 or more days of recording for each week of measurement and cows with a minimum of 3 repeated weekly measurements. Methane concentration was measured by 2 sniffer methods (Garnsworthy et al., 2012; Lassen et al., 2012): the nondispersive infrared $\mathrm{CH}_{4}$ sensor (Guardian NG, Edinburgh Instruments Ltd., Livingston, UK) in the research farms and the portable Fourier transform infrared Gasmet DX-4000 (Gasmet Technologies Oy, Helsinki, Finland) in the commercial farms. The concordance correlation coefficient between both sniffers when measuring $\mathrm{CH}_{4}$ concentration was 0.79 (Garnsworthy et al., 2019). Both methodologies were described and compared previously (Difford et al., 2016), where it was concluded that both instruments can be used interchangeably after calibration and standardization. $\mathrm{As}_{\mathrm{SH}}$ concentration (in parts per million) was not normally distributed, a natural logarithm (ln) transformation was used, and the ln was multiplied by 100 to avoid problems with the scale of the other traits. The phenotypic correlation between $\mathrm{CH}_{4}$ concentration and $\mathrm{CH}_{4}$ in grams per day based on a previous study on the same data was 0.85 , whereas the genetic correlation was 0.74 (C. I. V. Manzanilla-Pech, unpublished data). However, in this study, only the $\mathrm{CH}_{4}$ concentration trait was used to avoid artificially induced covariation between traits in multitrait estimators, as estimated $\mathrm{CH}_{4}$ in grams per day is a linear combination of the ratio $\mathrm{CH}_{4}: \mathrm{CO}_{2}$ concentration and the predictor traits ECM and BW (Madsen et al., 2010).

Weekly average records on BW and milk yield (MY) were collected between 1992 and 2016. Cows were located at Ammitsbøl Skovgaard research herd (Skovgaard, Vejle, Denmark) until 2000 and were subsequently relocated to the Danish Cattle Research Center in 2001 to 2016 as reported in Li et al. (2017). Cows were part of numerous nutritional experiments and diets that included primarily rolled barley, corn silage, grass clover silage, rapeseed meal, and soybean meal. The research barn Ammitsbøl Skovgaard was a tiestall system with twice-daily milking and sampling to measure milk quantity and components (fat and protein content). The Danish Cattle Research Center barn is a loose housing system with access to automatic milking systems (DeLaval International AB, Tumba, Sweden). Milk composition was determined using infrared technology at Eurofins (Vejen, Denmark) using CombiFoss equipment (Foss, Hillerød, Denmark). The automatic milking system was fitted with a weighing platform (Danvaegt, Hinnerup, Denmark) that recorded BW at 
each milking from which weekly averages were calculated (full description can be found in $\mathrm{Li}$ et al., 2017). For the 10 commercial farms, weekly average MY and milk components were available by the national recording scheme (RYK, Skejby, Denmark).

Energy-corrected milk was calculated using the following equation (Sjaunja et al., 1990):

$$
\begin{aligned}
\operatorname{ECM}(\mathrm{kg}) & =0.25 \mathrm{milk}(\mathrm{kg})+12.2 \mathrm{fat}(\mathrm{kg}) \\
& +7.7 \text { protein }(\mathrm{kg}) .
\end{aligned}
$$

\section{Genotypes and Pedigree}

Two sets of genotypes were available; one set $(1,747$ cows) was genotyped with 50k Illumina Bovine SNP50 (Illumina, San Diego, CA), and the other set (466 cows) was genotyped with EuroGenomics 10K LD chip (EuroGenomics, Amsterdam, the Netherlands). The genotypes were edited for quality control with Plink software (Purcell et al., 2007). Quality control included a minimum of 0.02 for minor allele frequency, a maximum of $10 \%$ genotypes per SNP missing, a maximum of $15 \%$ genotypes per animal missing, and HardyWeinberg disequilibrium significant at $P=0.001$. In addition, animals with duplicated genotypes, sex chromosome SNP, unmapped SNP, and SNP with duplicate or uncertain positions were deleted. Posteriorly, the LD chip genotypes were imputed to $50 \mathrm{~K}$ with FImpute software (Sargolzaei et al., 2014). After editing and removing duplicates, 1,962 cows with 38,253 SNP remained. The full pedigree contained the identification of the cow, sire, and dam for around 49,000 individuals. After pruning for noninformative animals, 25,701 animals remained. The cows with phenotypes could trace back ancestors on average 9 generations in the pruned pedigree.

\section{Variance Components and GEBV Estimation}

Variance components for $\mathrm{CH}_{4}, \mathrm{BW}$, and ECM were estimated using the AI-REML algorithm with DMU software (Version 6, Release 5.4; Madsen and Jensen, 2014). Genetic and phenotypic correlations used for the GEBV calculation were estimated through multivariate analysis between the traits in the full population using pedigree information.

To test the change in accuracies by including genotypic information, 2 methods were used: BLUP with only pedigree information and SSGBLUP with genotypes plus pedigree information. The GEBV for $\mathrm{CH}_{4}$ of each animal (through different scenarios and methods) were estimated using DMU (Madsen and Jensen, 2014) with BLUP and SSGBLUP. Both methods were implemented considering the same fixed effects and nongenetic random effects as in Equation 2. All SNP that passed quality control were used to calculate GRM according to VanRaden (2008), using the invgmatrix program included in DMU (Madsen and Jensen, 2014) together with the pedigree.

The BLUP and SSGBLUP in matrix notation with variance components estimated in Equation 2 and the inverse of relationship matrix $\mathrm{A}$ and $\mathrm{H}$, respectively, are:

$$
\mathbf{y}=\mathbf{X b}+\mathbf{Z}_{1} \mathbf{a}+\mathbf{Z}_{2} \mathbf{c}+\mathbf{e},
$$

where $\mathbf{y}$ is the vector of phenotypes; $\mathbf{b}$ represents the vector of fixed effects [herd, trial, year, season; lactation week modeled with the Wilmink function; type of sniffer (2 levels); and parity number as 1, 2, and 3+]; $\mathbf{X}$ is the incidence matrix relating observations with fixed effects; $\mathbf{a}$ is the vector of direct additive genetic effects; $\mathbf{Z}_{1}$ is the incidence matrix relating observations with random genetic effects; $\mathbf{c}$ is the vector of permanent environmental effects; $\mathbf{Z}_{2}$ is the incidence matrix relating observations with random permanent environmental effect; and $\mathbf{e}$ is the vector of residual effects. The models for BW and ECM were similar to Equation 2 but excluding the type of sniffer (Guardian or Gasmet) fixed effect. Distributions of the random effects are $\operatorname{var}(\mathbf{a})=\mathbf{A} \sigma_{a}^{2}$ for the BLUP method using only pedigree, where $\mathbf{A}$ is the pedigree relationship matrix and $\sigma_{a}^{2}$ is the additive genetic variance; $\operatorname{var}(\mathbf{a})=\mathbf{H} \sigma_{a}^{2}$ for the SSGBLUP method, where $\mathbf{H}$ is the combined pedigree and genomic relationship matrix and $\sigma_{a}^{2}$ is the additive genomic variance; $\operatorname{var}(\mathbf{c})=\mathbf{I} \sigma_{c}^{2}$, where $\mathbf{I}$ is the identity matrix of order equal to the number of individuals with records and $\sigma_{c}^{2}$ is the permanent environmental variance; and $\operatorname{var}(\mathbf{e})=\mathbf{I} \sigma_{e}^{2}$, where $\mathbf{I}$ is an identity matrix of an order equal to the number of observations and $\sigma_{e}^{2}$ is the residual variance. The inverse of the $\mathrm{H}$-matrix, $\mathbf{H}^{-1}$, was calculated with the following equation (Aguilar et al., 2010; Christensen and Lund, 2010):

$$
\mathbf{H}^{-1}=\mathbf{A}^{-1}+\left[\begin{array}{cc}
0 & 0 \\
0 & \lambda\left(\mathbf{G} w^{-1}-\mathbf{A}_{22}^{-1}\right)
\end{array}\right],
$$

where $\mathbf{A}^{-1}$ is the inverse of the pedigree relationship matrix; $\lambda$ is the value of 0.95 for lambda, $\mathbf{G}^{-1}$ is the inverse of the GRM, $w$ is the relative weight on the polygenic effect, and $\mathbf{A}_{22}^{-1}$ is the inverse of the pedigree relationship matrix among genotyped animals. 


\section{Scenarios and Sub-Scenarios}

Table 1 illustrates all the scenarios, sub-scenarios, and (co)variances used for each scenario. Thirteen sub-scenarios across 5 scenarios were performed, first a base single-trait scenario $\left(1, \mathrm{CH}_{4}\right)$, where only $\mathrm{CH}_{4}$ information was considered. From scenario 2 to 5 , each scenario has 3 sub-scenarios depending on the predictor trait included: (a) BW, (b) ECM, and (c) BW+ECM. Thus, the second scenario assumes the absence of $\mathrm{CH}_{4}$ information, but with information available on predictor traits in the reference population: (2a) BW_OR, (2b) ECM_OR, and (2c) BW+ECM_OR. The third scenario assumes the absence of $\mathrm{CH}_{4}$ information, but with information available on predictor traits in validation and reference population [(3a) BW_VR, (3b) ECM_VR, (3c) BW+ECM_VR]. The fourth scenario assumes the presence of information on $\mathrm{CH}_{4}$ and predictor traits on the reference population [(4a) $\mathrm{CH}_{4}+\mathrm{BW}$
OR, (4b) $\mathrm{CH}_{4}+\mathrm{ECM} \_\mathrm{OR},(4 \mathrm{c}) \mathrm{CH}_{4}+\mathrm{BW}+\mathrm{ECM} \_\mathrm{OR}$. Finally, the fifth scenario assumes the presence of information of $\mathrm{CH}_{4}$ in the reference population and predictor traits in both validation and reference population [(5a) $\mathrm{CH}_{4}+\mathrm{BW} \_\mathrm{VR},(5 \mathrm{~b}) \mathrm{CH}_{4}+\mathrm{ECM} \_\mathrm{VR},(5 \mathrm{c})$ $\mathrm{CH}_{4}+\mathrm{BW}+$ ECM_VR].

\section{Cross-Validation Groups}

All 13 sub-scenarios across the 2 methods (BLUP and SSGBLUP) were validated using cross-validation, where the population of genotyped individuals was divided into 10 subsets, ensuring all paternal half-sibs were in the same group. The assignment to the groups was made by sire, using stratified random sampling, which was undertaken in 2 steps. First, the sires of genotyped animals were ranked from the highest to the lowest by number of daughters with $\mathrm{CH}_{4}$ records. Then, from every set of 10 subsequent sires, 1 sire was

Table 1. Different scenarios and sub-scenarios performed per method (BLUP, SSGBLUP) ${ }^{1}$

\begin{tabular}{|c|c|c|c|c|c|c|}
\hline $\begin{array}{l}\text { Scenario } \\
\text { description }\end{array}$ & $\begin{array}{l}\text { Sub-scenario } \\
\text { abbreviation }^{2}\end{array}$ & $\begin{array}{l}\text { Type of } \\
\text { analysis }\end{array}$ & $\begin{array}{l}\text { (Co)variances } \\
\text { used to obtain } \\
\mathrm{GEBV}^{3}\end{array}$ & $\begin{array}{l}\text { Validation } \\
\text { trait }\end{array}$ & $\begin{array}{l}\text { Information } \\
\text { included } \\
\text { in the validation } \\
\text { population }\end{array}$ & $\begin{array}{l}\text { Information } \\
\text { included } \\
\text { in reference } \\
\text { population }\end{array}$ \\
\hline 1. Base & 1. $\mathrm{CH}_{4}$ & Univariate & Var $\mathrm{CH}_{4}$ & $\mathrm{CH}_{4}$ & - & $\mathrm{CH}_{4}$ \\
\hline $\begin{array}{l}\text { 2. } \mathrm{No} \mathrm{CH}_{4} \text {, } \\
\text { predictor }\end{array}$ & 2a. BW & Bivariate & $\begin{array}{l}\text { Var } \mathrm{CH}_{4}, \text { Var BW, } \\
\text { Cov } \mathrm{CH}_{4}-\mathrm{BW}\end{array}$ & $\mathrm{CH}_{4}$ & - & $\mathrm{BW}$ \\
\hline \multirow[t]{2}{*}{$\begin{array}{l}\text { traits only in } \\
\text { reference }\end{array}$} & 2b. ECM & Bivariate & $\begin{array}{l}\text { Var } \mathrm{CH}_{4}, \text { Var ECM, } \\
\text { Cov } \mathrm{CH}_{4}-\mathrm{ECM}\end{array}$ & & & ECM \\
\hline & 2c. $\mathrm{BW}+\mathrm{ECM}$ & Trivariate & $\begin{array}{l}\text { Var } \mathrm{CH}_{4}, \text { Var BW, } \\
\text { Var ECM, Cov } \mathrm{CH}_{4}{ }^{-} \\
\text {BW Cov } \mathrm{CH}_{4}-\mathrm{ECM} \text {, } \\
\text { Cov BW-ECM }\end{array}$ & & & $\mathrm{BW}$ and $\mathrm{ECM}$ \\
\hline \multirow{3}{*}{$\begin{array}{l}\text { 3. } \mathrm{No} \mathrm{CH}_{4} \text {, } \\
\text { predictor traits } \\
\text { on validation } \\
\text { and reference }\end{array}$} & 3a. BW & Bivariate & $\begin{array}{l}\text { Var } \mathrm{CH}_{4}, \text { Var BW, } \\
\text { Cov } \mathrm{CH}_{4}-\mathrm{BW}\end{array}$ & $\mathrm{CH}_{4}$ & $\mathrm{BW}$ & $\mathrm{BW}$ \\
\hline & 3b. ECM & Bivariate & $\begin{array}{l}\text { Var } \mathrm{CH}_{4}, \text { Var ECM, } \\
\text { Cov } \mathrm{CH}_{4}-\mathrm{ECM}\end{array}$ & & ECM & ECM \\
\hline & 3c. BW + ECM & Trivariate & $\begin{array}{l}\text { Var } \mathrm{CH}_{4}, \text { Var BW, } \\
\text { Var ECM, Cov } \mathrm{CH}_{4^{-}} \\
\mathrm{BW} \text { Cov } \mathrm{CH}_{4}-\mathrm{ECM} \text {, } \\
\text { Cov BW-ECM }\end{array}$ & & BW and ECM & BW and ECM \\
\hline \multirow{3}{*}{$\begin{array}{l}\text { 4. } \mathrm{CH}_{4} \text {, } \\
\text { predictor traits } \\
\text { only reference }\end{array}$} & 4a. $\mathrm{CH}_{4}+$ BW_OR & Bivariate & $\begin{array}{l}\text { Var } \mathrm{CH}_{4}, \text { Var BW, } \\
\text { Cov } \mathrm{CH}_{4}-\mathrm{BW}\end{array}$ & $\mathrm{CH}_{4}$ & - & $\mathrm{CH}_{4}$ and $\mathrm{BW}$ \\
\hline & 4b. $\mathrm{CH}_{4}+$ ECM_OR & Bivariate & $\begin{array}{l}\text { Var } \mathrm{CH}_{4}, \text { Var ECM, } \\
\text { Cov } \mathrm{CH}_{4}-\mathrm{ECM}\end{array}$ & & & $\mathrm{CH}_{4}$ and $\mathrm{ECM}$ \\
\hline & $\begin{array}{l}\text { 4c. } \mathrm{CH}_{4}+\mathrm{BW}+\mathrm{ECM}_{-} \\
\mathrm{OR}\end{array}$ & Trivariate & $\begin{array}{l}\text { Var } \mathrm{CH}_{4}, \text { Var BW, } \\
\text { Var ECM, Cov } \mathrm{CH}_{4}- \\
\text { BW Cov } \mathrm{CH}_{4}-\mathrm{ECM}^{-} \\
\text {Cov BW-ECM }\end{array}$ & & & $\begin{array}{l}\mathrm{CH}_{4}, \mathrm{BW} \text {, and } \\
\text { ECM }\end{array}$ \\
\hline \multirow{3}{*}{$\begin{array}{l}5 . \mathrm{CH}_{4} \text {, } \\
\text { predictor trait } \\
\text { on validation }+ \\
\text { reference }\end{array}$} & 5a. $\mathrm{CH}_{4}+\mathrm{BW}_{-} \mathrm{VR}$ & Bivariate & $\begin{array}{l}\text { Var } \mathrm{CH}_{4}, \text { Var BW, } \\
\text { Cov } \mathrm{CH}_{4}-\mathrm{BW}\end{array}$ & $\mathrm{CH}_{4}$ & BW & $\mathrm{CH}_{4}$ and $\mathrm{BW}$ \\
\hline & 5b. $\mathrm{CH}_{4}+$ ECM_VR & Bivariate & $\begin{array}{l}\text { Var } \mathrm{CH}_{4}, \text { Var ECM, } \\
\text { Cov } \mathrm{CH}_{4}-\mathrm{ECM}\end{array}$ & & ECM & $\mathrm{CH}_{4}$ and $\mathrm{ECM}$ \\
\hline & $\begin{array}{l}\text { 5c. } \mathrm{CH}_{4}+\mathrm{BW}+\mathrm{ECM}_{-} \\
\mathrm{VR}\end{array}$ & Trivariate & $\begin{array}{l}\text { Var } \mathrm{CH}_{4} \text {, Var BW, } \\
\text { Var ECM, Cov } \mathrm{CH}_{4^{-}} \\
\text {BW Cov } \mathrm{CH}_{4}-\mathrm{ECM} \text {, } \\
\text { Cov BW-ECM }\end{array}$ & & BW and ECM & $\begin{array}{l}\mathrm{CH}_{4}, \mathrm{BW}, \text { and } \\
\mathrm{ECM}\end{array}$ \\
\hline
\end{tabular}

${ }^{1}$ SSGBLUP $=$ single-step genomic BLUP.

${ }^{2} \mathrm{CH}_{4}=$ methane concentration; $\mathrm{OR}=$ only reference; $\mathrm{VR}=$ validation + reference.

${ }^{3} \mathrm{GEBV}=$ genomic EBV. 
Table 2. Numbers of sires, cows in validation and reference populations, and $\mathrm{CH}_{4}, \mathrm{BW}$, and ECM records in reference population per crossvalidation group

\begin{tabular}{|c|c|c|c|c|c|c|c|c|c|c|}
\hline \multirow[b]{2}{*}{ Population } & \multicolumn{10}{|c|}{ Cross-validation group } \\
\hline & 1 & 2 & 3 & 4 & 5 & 6 & 7 & 8 & 9 & 10 \\
\hline Cows in validation & 226 & 233 & 206 & 202 & 233 & 222 & 197 & 209 & 220 & 213 \\
\hline Cows in reference & 2,004 & 1,997 & 2,024 & 2,028 & 1,997 & 2,008 & 2,033 & 2,021 & 2,010 & 2,017 \\
\hline $\mathrm{CH}_{4}$ records in reference & 12,800 & 12,652 & 13,414 & 12,946 & 12,843 & 12,158 & 13,393 & 12,927 & 12,724 & 12,704 \\
\hline BW records in reference & 57,550 & 56,089 & 56,737 & 56,259 & 59,248 & 55,062 & 56,212 & 57,437 & 58,589 & 55,850 \\
\hline
\end{tabular}

randomly allocated to 1 of the 10 groups. Thus, the 10 validation groups were similar in terms of the proportion of sires, number of cows with genotypes and the total number of records. The number of sires and cows in the cross-validation groups is shown in Table 2. The average number of cows per sire was 4 , and the total number of sires was 566. For each of the validation groups, GEBV for $\mathrm{CH}_{4}$ were predicted after excluding the respective $\mathrm{CH}_{4}$ phenotypes from the analysis, using phenotypes of the other 9 groups as the reference population.

\section{Accuracy and Bias Calculation}

Adjusted phenotypes for $\mathrm{CH}_{4}$ were calculated as the sum of the solutions per animal for genetic effects and permanent environmental effects with the full database, using all fixed effects in Equation 2. In this way, a unique phenotype per animal closer to the true phenotype was available instead of multiple true phenotypes. The accuracies were calculated via cross-validation per sub-scenario as the correlation between the adjusted phenotype for $\mathrm{CH}_{4}$ and the GEBV for $\mathrm{CH}_{4}$ divided by the formula adapted from Mrode (2013) computed to calculate the accuracy for repeated records:

$$
\text { Accuracy }=\frac{r}{\sqrt{\frac{n \mathrm{~h}^{2}}{1+(n-1) t}}},
$$

where $r$ is the correlation between the adjusted phenotype and the GEBV, $n$ is the average number of repeated records per animal per cross-validation group (6); $\mathrm{h}^{2}$ is the heritability of the $\mathrm{CH}_{4}(0.14 \pm 0.05$; see Results and Discussion); and $t$ is the repeatability of $\mathrm{CH}_{4}$ calculated as sum of the genetic and permanent environmental variances divided by the phenotypic variance (0.51). Accuracies were averaged across the 10 validation groups. Standard errors of accuracies per scenario were defined as the standard deviation of the accuracy across all validation groups divided by the square root of the number of validation groups (10). Slopes of regression (linear regression coefficients) of the adjusted phenotypes on the GEBV were calculated per method and per sub-scenario as a measure of the bias in terms of the variance in GEBV. Additionally, average pairwise comparison correlations between GEBV obtained from all 13 scenarios across 10 validation groups were calculated as additional measure to determine the similarities among the scenarios.

\section{RESULTS AND DISCUSSION}

\section{Estimated Genetic Parameters}

Descriptive statistics for $\mathrm{CH}_{4}, \mathrm{BW}$, and ECM are presented in Table 3. Energy-corrected milk and BW values are consistent with northern European cattle (Manzanilla-Pech et al., 2014; Li et al., 2018). Estimated variances, heritability, repeatability, and phenotypic and genetic correlations for $\mathrm{CH}_{4}, \mathrm{BW}$, and $\mathrm{ECM}$ are shown in Table 4 . The heritability estimate for $\mathrm{CH}_{4}$ was 0.14 , within the range of estimates from literature $(0.10$ to 0.30) from smaller studies (van Engelen et al., 2018, Difford et al., 2020). Repeatability for $\mathrm{CH}_{4}$ was 0.51 , meaning that the permanent environmental variation explained a higher proportion of the variance than the genetics for this trait. The estimated heritability for ECM of 0.37 in the current study was in the range of previously reported heritabilities, ranging between 0.27 and 0.54 (Hüttman et al., 2008; Buttchereit et al., 2011; Manzanilla-Pech et al., 2014; Li et al., 2018; Interbull, 2018). Likewise, estimated heritability for BW (0.58) was in the range of estimates in the literature ranging from 0.43 to 0.65 (Berry et al., 2003; Muller et al., 2006; Dechow et al., 2010; Manzanilla-Pech et al., 2014; Li et al., 2018). The genetic correlation between $\mathrm{CH}_{4}$ emissions and BW (0.50) was close to value of 0.42 reported by Breider et al. (2018) using the $\mathrm{SF}_{6}$ tracer gas method for measuring $\mathrm{CH}_{4}$. The genetic correlation between $\mathrm{CH}_{4}$ and ECM (0.60) in this study was higher than the genetic correlation (0.45) previously reported 
Table 3. Descriptive statistics for $\mathrm{CH}_{4}$, BW, and ECM

\begin{tabular}{lcccrrr}
\hline Trait & No. of cows & No. of records & Mean & SD & Minimum & Maximum \\
\hline $\mathrm{CH}_{4}{ }^{1}$ & 2,230 & 14,125 & 572.6 & 47.1 & 450.0 & 699.9 \\
$\mathrm{BW}(\mathrm{kg})$ & 2,714 & 61,667 & 641.1 & 75.2 & 387.0 & 899.9 \\
$\mathrm{ECM}(\mathrm{kg})$ & 2,702 & 61,610 & 32.9 & 8.5 & 10.00 & 64.8 \\
\hline
\end{tabular}

${ }^{1} \mathrm{CH}_{4}$ is the natural logarithm of ppm, multiplied by 100 .

by Lassen and Løvendahl (2016) for $\mathrm{CH}_{4}$ in grams per day and ECM in Danish Holstein but lower than 0.74 reported by Breider et al. (2018) between $\mathrm{CH}_{4}$ grams per day and MY in Australian Holstein cows. Also, there is an additional increase in accuracy with multivariate analysis resulting from better connections in the data due to residual covariance between traits (Thompson and Meyer, 1986). These moderate and positive genetic correlations could be used to increase the accuracy of estimation for GEBV of $\mathrm{CH}_{4}$ when including $\mathrm{BW}$ and ECM information on reference animals in the genomic prediction. Furthermore, these genetic correlations will be needed to calculate the correlated response and the genetic gain of these traits in a multitrait index.

\section{Accuracies of GEBV for $\mathrm{CH}_{4}$}

Accuracies of prediction of GEBV for $\mathrm{CH}_{4}$ averaged across 10 validation groups per method and scenario for BLUP and SSGBLUP are shown in Figure 1.

Per Method. The added information from including genotypes is expected to increase the accuracies; however, this increase was only significant (based on SE) in the base scenario and in sub-scenario 4a. Accuracies of EBV for $\mathrm{CH}_{4}$ for the base scenario were 0.32 for BLUP and 0.42 for SSGBLUP. For 7 of the 13 scenarios, accuracies of GEBV obtained using SSGBLUP were numerically higher than those obtained using BLUP, as expected based on reports in dairy cattle over numerous traits (Hayes and Goddard, 2008; VanRaden et al., 2009). However, based on the magnitude of standard errors of both methods, these results should be interpreted with caution.
Given the globally insufficient number of animals with $\mathrm{CH}_{4}$ data available, few studies have reported accuracies of GEBV for $\mathrm{CH}_{4}$ in cattle. Hayes et al. (2016) reported accuracies between 0.26 and 0.38 for $\mathrm{CH}_{4}$ traits in Angus beef cattle $\left(\mathrm{CH}_{4}\right.$ production rate, methane yield, and 4 definitions of residual methane) using GBLUP and BayesR. Accuracies reported in this current study were higher than those reported by de Haas et al. (2011) for predicted enteric $\mathrm{CH}_{4}$ emission in Holstein cattle using genomic information (0.37) and pedigree information (0.21).

Across multitrait scenarios, accuracy for BLUP method ranged from 0.10 to 0.72 , whereas for SSGBLUP it ranged from 0.12 to 0.75 . These results have shown that multitrait prediction performed similarly across methods and on average better than the singletrait scenario. In this study, adding genotype information (SSGBLUP) only significantly increased the accuracy for the single-trait scenario (0.42). This could be partially due to only two-thirds of the animals with predictor trait information having genotypes.

Per Scenario and Sub-Scenario. The higher accuracies of GEBV of $\mathrm{CH}_{4}$ due to multitrait genomic prediction compared with single-trait genomic prediction are in agreement with previous findings in other traits in Holstein cows, such as linear type traits (Tsuruta et al., 2011), conception rate (Aguilar et al., 2011), and detailed milk protein composition (Gebreyesus et al., 2016). On average, scenarios with $\mathrm{CH}_{4}$ information performed better than scenarios without $\mathrm{CH}_{4}$, as in the absence of $\mathrm{CH}_{4}$ records, the accuracy of estimated GEBV relies entirely on the genetic correlations between $\mathrm{CH}_{4}$ and routinely recorded predictor traits. This can

Table 4. Estimated genetic, permanent environmental, and residual variances, repeatability, heritability (diagonal), and genetic (below diagonal) and phenotypic (above diagonal) correlations (SE in parentheses) for $\mathrm{CH}_{4}, \mathrm{BW}$, and ECM

\begin{tabular}{|c|c|c|c|c|c|c|c|}
\hline \multirow[b]{2}{*}{ Trait } & \multicolumn{3}{|c|}{ Variance } & \multirow[b]{2}{*}{ Repeatability } & \multicolumn{3}{|c|}{ Correlations } \\
\hline & Genetic & $\begin{array}{c}\text { Permanent } \\
\text { environmental }\end{array}$ & Residual & & $\mathrm{CH}_{4}$ & BW & ECM \\
\hline $\mathrm{CH}_{4}$ & 147.6 & 398.9 & 500.4 & 0.51 & $0.14(0.05)$ & $0.15(0.01)$ & $0.25(0.02)$ \\
\hline BW & $2,240.7$ & $1,074.8$ & 547.7 & 0.86 & $0.50(0.10)$ & $0.58(0.03)$ & $0.17(0.02)$ \\
\hline ECM & 19.1 & 15.5 & 20.4 & 0.62 & $0.60(0.10)$ & $0.26(0.07)$ & $0.37(0.03)$ \\
\hline
\end{tabular}


be translated as the GEBV is the correlated response of $\mathrm{CH}_{4}$ when including $\mathrm{BW}$ and ECM information. However, the scenarios without $\mathrm{CH}_{4}$ information in the reference population could result in a phenotype for $\mathrm{CH}_{4}$ that is only based on ECM and BW, and selecting for this phenotype would likely lead to an unfavorable correlated response reducing ECM and BW if these traits are not included in the selection index.

Furthermore, there are some important messages to point out based on the accuracies obtained in this study across scenarios. First, the scenarios without information on $\mathrm{CH}_{4}$ but with information on predictor traits in both validation and reference population (3) achieved similar accuracies than the scenarios with $\mathrm{CH}_{4}$ records and only predictor traits on only the reference population (4). However, the genetic gains achieved via each scenario would vary greatly. In scenario 3 with no $\mathrm{CH}_{4}$, all the genetic variation of $\mathrm{CH}_{4}$ comes from ECM and BW, implying that a reduction in $\mathrm{CH}_{4}$ will in practice be coming from selecting smaller animals that produce less milk, which is counterintuitive to the aim of profitable dairy production. Conversely, scenario 4 with $\mathrm{CH}_{4}$ information has the full genetic variation of $\mathrm{CH}_{4}$, including the fraction that is not solely explained by ECM and BW. In principle, in scenario 4 with $\mathrm{CH}_{4}$ information included, using all traits in a selection index can achieve selection for lower or reduced emitting animals when increasing or maintaining milk production [i.e., improved methane intensity $\left(\mathrm{CH}_{4} / \mathrm{L}\right.$ of ECM $)$ ]. Second, scenario 5, which has $\mathrm{CH}_{4}$ information only in the reference population plus the correlated predictor traits (ECM and BW) in both reference and validation population achieved the highest accuracies. However, because GEBV are usually predicted for young animals before they have their own phenotypes, scenario 5 is not closely aligned with genomic selection schemes in practice, where such a scheme is more related to scenario 4. Yet, this scenario could be important when trying to predict $\mathrm{CH}_{4}$ in second or later lactation cows (with ECM and BW information available).

Across sub-scenarios, we observed that adding information on BW does not improve the accuracy of prediction of $\mathrm{CH}_{4}$ compared with adding ECM. This discrepancy in accuracies between predictor traits can be explained by the relatively higher genetic correlation between $\mathrm{CH}_{4}$ and ECM compared with $\mathrm{CH}_{4}$ and BW (Table 4). In addition, sub-scenarios with BW and ECM information in both reference and validation populations performed better than the scenarios having the extra information on only the reference population. Similarly, Pszczola et al. (2013) reported higher accuracies of prediction for DMI in Holstein

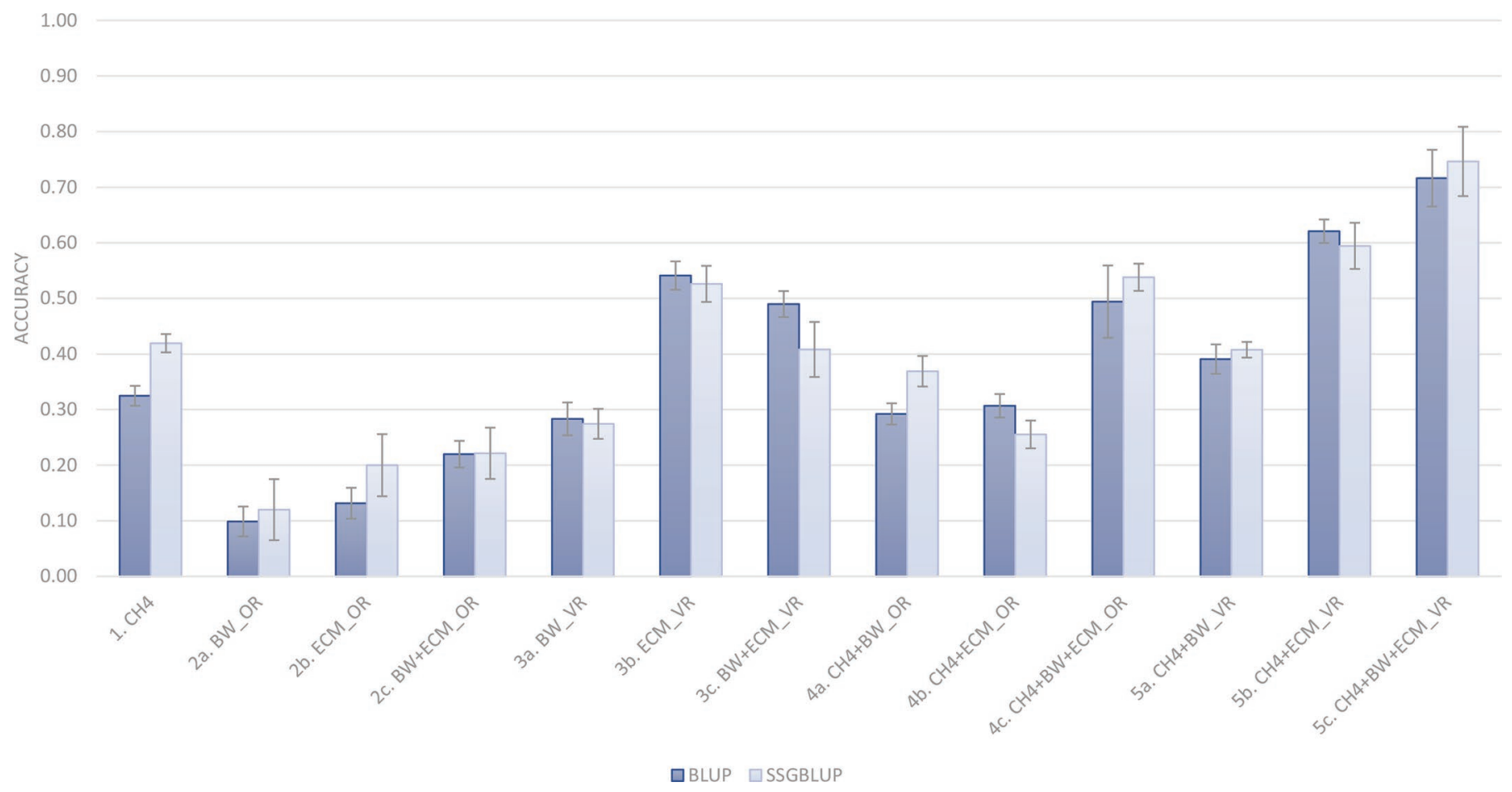

Figure 1. Accuracies of prediction of genomic EBV for methane, averaged across 10 validation groups per sub-scenario for BLUP and singlestep genomic BLUP (SSGBLUP). $\mathrm{CH}_{4}=$ methane concentration, $\mathrm{OR}=$ only reference, $\mathrm{VR}=$ validation + reference. Error bars represent SE. 
cows when including predictor traits in the validation and reference population compared with including them only in the reference population. Additionally, in this study the sub-scenarios including both BW and ECM achieved higher accuracies than the inclusion of only one of them, except for the scenario without $\mathrm{CH}_{4}$ information but with BW and ECM in both reference and validation population, where a marginal stochastic difference was reported. Likewise, Pszczola et al. (2013) reported higher accuracies $(0.62-0.63)$ when both traits were included compared with including only one trait (0.47-0.57) for BLUP and GBLUP.

As mentioned before, the gain in accuracy of GEBV of the goal trait in multitrait genomic prediction is conditional on the magnitude of the genetic correlations between the goal trait and the predictor traits included in the multitrait analysis. Jia and Jannink (2012) stated that the relative difference in the heritability of the goal trait to predictor trait(s), as in our study (Table 4), also influences the accuracy of the goal trait GEBV, where the gain in accuracy is higher when the heritability of the goal trait is relatively lower than the predictor traits. Within this context, Jia and Jannink (2012) showed the effect of genetic correlation between the traits on the prediction accuracy of the goal trait depends on the magnitude of the heritability estimates of the goal trait, being more remarkable when the heritability of the goal trait is low (0.1) and almost imperceptible when the heritability of the goal trait is high (0.5). This means that for a trait with low heritability it is more important to have higher correlation with the other trait(s) than for a trait with moderate to high heritability. Additionally, Calus and Veerkamp (2011) stated that lowly heritable traits could borrow information from correlated highly heritable traits and consequently achieve higher prediction accuracy.

\section{Bias of GEBV for $\mathrm{CH}_{4}$}

Coefficients of regression are a measure of slope bias in terms of the variance of the GEBV relative to the adjusted phenotype. Figure 2 shows the coefficients of regression of the adjusted phenotype on the GEBV across methods and scenarios. Coefficients larger than 1 indicate underestimation and smaller than 1 indicate overestimation.

Per Method. On average, the regression coefficient for the base scenario (single trait) was not different from the regression coefficients estimated for SSGBLUP, indicating that there is practically no bias on the estimation of the breeding values. For the multitrait scenarios, the regression coefficients varied widely within methods (between 0.34 and 1.02 for BLUP, and 0.48 and 0.95 for SSGBLUP). The regression coefficients did not vary so much across methods for most scenarios.

Per Scenario and Sub-Scenario. In general, the regression coefficients performed consistently per scenario and sub-scenario, similar to the accuracies.

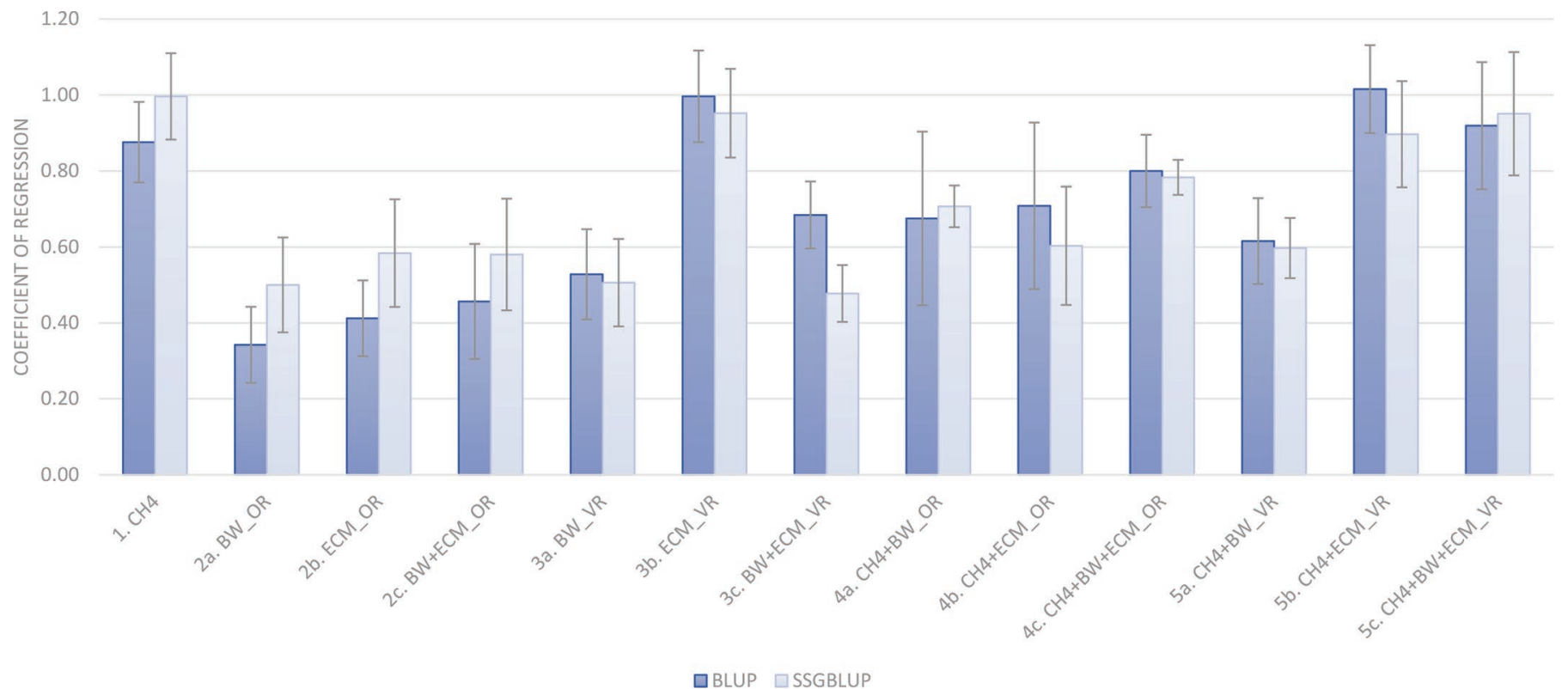

Figure 2. Bias (coefficient of regression) of genomic EBV for methane, averaged across 10 validation groups per sub-scenario for BLUP and single-step genomic BLUP. $\mathrm{CH}_{4}=$ methane concentration, $\mathrm{OR}=$ only reference, $\mathrm{VR}=$ validation + reference. Error bars represent $\mathrm{SE}$. 
The multitrait scenarios ranked as follows: scenario 2 ranged from 0.34 to 0.64 ; scenario 3 ranged from 0.48 to 1.11 ; scenario 4 ranged from 0.60 to 0.88 ; scenario 5 ranged from 0.60 to 1.06. Sub-scenarios from scenario 3 , without $\mathrm{CH}_{4}$ and with information on $\mathrm{BW}$ and ECM only in the reference population, showed more bias than the other scenarios. Additionally, sub-scenarios from scenario 4, without phenotypic observations for BW and ECM in the validation population, showed more bias than scenarios with phenotypic observations for BW and ECM in the validation population as a result of a possible incorrect scale of the variance of the GEBV (Pszczola et al., 2013). Sub-scenarios from scenarios 5, with $\mathrm{CH}_{4}$ and information on BW and ECM in both validation and reference population, were almost unbiased with regression coefficients closer to unity compared with the other scenarios. In addition, Song et al. (2019) reported that bias reduces in a multitrait genomic prediction (compared with the single trait) when the genetic correlation between the traits is high.

Finally, in terms of bias, our study has also shown that 4 of the 5 sub-scenarios with better accuracies of GEBV also had the least biased regression coefficient estimates, without significant differences from the unity. The 4 sub-scenarios were 3b (ECM_VR; 0.95-1.11), 4c (CH4+BW+ECM_OR; 0.78-0.88), 5b (CH4+ECM_ VR; 0.90-1.02), and 5c (CH4+BW+ECM_VR; 0.92$1.06)$.

\section{Correlations Between Scenarios}

In genomic prediction it is common practice to report accuracies and bias of GEBV predictions, but these metrics only reflect the correlation between the predicted GEBV and the true phenotype (in this case the adjusted phenotype) corrected by the heritability of the trait. However, when using multitrait genomic prediction, it is important to understand where the variation of GEBV comes from. One way to do this is calculating the correlation between the GEBV from the different scenarios with the GEBV from the single-trait (base) scenario. In Table 5, we report the average correlations between $\mathrm{CH}_{4}$ GEBV estimated by SSGBLUP method per scenario across 10 cross-validation groups. The correlations between the GEBV from the multitrait scenarios and the GEBV from the base scenario (single trait) used as a proxy for the best estimate of the true GEBV of $\mathrm{CH}_{4}$ clearly discriminated between the scenarios which included $\mathrm{CH}_{4}$ records in the reference population or not. For instance, the correlations between the base scenario and scenarios 2 and 3 were low (0.18-0.33), whereas scenarios 4 and 5, which in-
Table 5. Average pairwise comparison correlations between genomic EBV estimated by SSGBLUP method per scenario and sub-scenario across 10 cross-validation groups ${ }^{1}$

\begin{tabular}{lcccc}
\hline $\begin{array}{l}\text { Scenario/ } \\
\text { sub-scenario }\end{array}$ & 1 & $\begin{array}{c}2 \\
\mathrm{~b} \mathrm{c}\end{array}$ & $\begin{array}{c}3 \\
\mathrm{a} \mathrm{b} \mathrm{c}\end{array}$ & $\begin{array}{c}4 \\
\mathrm{a} \mathrm{b} \mathrm{c}\end{array}$ \\
\hline 1 & & & & \\
2 & & & & \\
$\mathrm{a}$ & 0.18 & & & \\
$\mathrm{~b}$ & 0.33 & & & \\
$\mathrm{c}$ & 0.25 & & & \\
3 & & & & \\
$\mathrm{a}$ & 0.17 & 0.55 & & \\
$\mathrm{~b}$ & 0.22 & 0.53 & & \\
$\mathrm{c}$ & 0.17 & 0.28 & & \\
4 & & & & \\
$\mathrm{a}$ & 0.79 & 0.61 & 0.39 & \\
$\mathrm{~b}$ & 0.81 & 0.67 & 0.44 & \\
$\mathrm{c}$ & 0.72 & 0.53 & 0.23 & \\
5 & & & & \\
$\mathrm{a}$ & 0.67 & 0.45 & 0.81 & 0.73 \\
$\mathrm{~b}$ & 0.68 & 0.46 & 0.85 & 0.72 \\
$\mathrm{c}$ & 0.41 & 0.32 & 0.78 & 0.70 \\
\hline
\end{tabular}

${ }^{1}$ SSGBLUP $=$ single-step genomic BLUP. OR $=$ only reference; $\mathrm{VR}$ $=$ validation + reference. $1=$ base scenario. $2 \mathrm{a}=\mathrm{BW} \mathrm{OR}: 2 \mathrm{~b}=$ ECM_OR; $2 \mathrm{c}=\mathrm{BW}+\mathrm{ECM} \_$OR. 3a $=$BW_VR; 3b = ECM_VR; 3c $=\mathrm{BW}+\mathrm{ECM} \_\mathrm{VR} .4 \mathrm{a}=\mathrm{CH}_{4}+\mathrm{BW} \_\mathrm{OR} ; 4 \mathrm{~b}=\mathrm{CH}_{4}+\mathrm{ECM} \_\mathrm{OR} ; 4 \mathrm{c}=$ $\mathrm{CH}_{4}+\mathrm{BW}+\mathrm{ECM} \_\mathrm{OR} .5 \mathrm{a}=\mathrm{CH}_{4}+\mathrm{BW} \_\mathrm{VR} ; 5 \mathrm{~b}=\mathrm{CH}_{4}+\mathrm{ECM} \_\mathrm{VR} ; 5 \mathrm{c}$ $=\mathrm{CH}_{4}+\mathrm{BW}+\mathrm{ECM} \_\mathrm{VR}$.

cluded $\mathrm{CH}_{4}$ in the reference population, where moderate to high (0.41-0.81). Furthermore, when comparing multitrait scenarios with and without $\mathrm{CH}_{4}$ (i.e., scenarios 2 vs. 4 and scenarios 3 vs. 5) the correlations are moderate to high, but not close to the unity. This result demonstrates that including $\mathrm{CH}_{4}$ information in the reference population is also adding additional information over and above ECM and BW. Scenario 3 , which performed similarly to scenario 4 in terms of accuracy and bias, had the poorest correlations with the base scenario GEBV (0.17-0.22). Promisingly, scenario 4, which is the most closely aligned to genomic selection schemes in practice and is the most likely to result in restricted $\mathrm{CH}_{4}$ with increasing milk production (i.e., dilution of $\mathrm{CH}_{4}$ ), had the highest correlations (0.72-0.81) with the base scenario.

\section{Implications}

In terms of gain in accuracy (in percentage) compared with the base scenario, our results have shown that including information on ECM and BW can increase the accuracy of GEBV for $\mathrm{CH}_{4}$ from $29 \%$ (scenario 4) up to $90 \%$ (scenario 5). However, the most feasible multitrait scenario, not only in terms of increased accuracy compared with the single-trait scenario but also one that could be used in practice when predicting $\mathrm{CH}_{4}$ for young candidates, is the scenario with $\mathrm{CH}_{4}$ and information 
on ECM and BW only in the reference population. Furthermore, we should be aware that part of the gain in accuracy when using ECM to predict $\mathrm{CH}_{4}$ is partially due to the higher accuracy of predictions for ECM, which were 0.50 and 0.65 for the base scenario (BLUP and SSGBLUP, respectively), much higher than the estimates for $\mathrm{CH}_{4}$. Moreover, the increase in accuracy using predictor traits in a multitrait approach has a plateau, meaning that there is a maximum of improvement that can be achieved by adding information on correlated traits. In addition, although using only ECM and $\mathrm{BW}$ records to predict $\mathrm{CH}_{4}$ in the absence of $\mathrm{CH}_{4}$ records leads to increased individual accuracies in $\mathrm{CH}_{4}$, this scenario can lead to a reduction of methane only at the cost of genetic gain for MY. Therefore, recording $\mathrm{CH}_{4}$ in more animals remains a priority. To restrict or reduce gain in $\mathrm{CH}_{4}$ without reducing gains in ECM or BW, a multitrait selection index is needed where all the economically important traits are included. A recent study (C. I. V. Manzanilla-Pech, unpublished data) shows that is possible to reduce methane and still have a positive genetic gain on ECM using 2 strategies, either applying a penalization (negative economic value for $\mathrm{CH}_{4}$ ) or by including a negative economic value for residual feed intake. Both strategies would lead to a reduction on $\mathrm{CH}_{4}$ without compromising the genetic gain on ECM and will represent an improvement in terms of $\mathrm{CH}_{4}$ per liter of milk.

Finally, is it well known that heritability is a determinant factor for the calculation of the optimal reference population size, and this is directly proportional to the maximum accuracy achieved in the genomic prediction (Daetwyler et al., 2010). Given that in the $\mathrm{CH}_{4}$ case both are limited (low heritability and small reference population size), it is recommended to investigate the optimal reference population size (and structure) that maximize the accuracy of prediction of GEBV for $\mathrm{CH}_{4}$ with the current heritability. Finally, there are other important traits highly correlated with $\mathrm{CH}_{4}$ that could contribute to increase the accuracy of prediction of GEBV for $\mathrm{CH}_{4}$, such as feed intake, feed efficiency (residual feed intake), and energy balance, among others. However, given that these are scarcely recorded traits, collecting information on them and further investigating on their interactions would be needed.

\section{CONCLUSIONS}

Multitrait genomic prediction leads to higher prediction accuracy than traditional single-trait genomic prediction, particularly when predictor traits are highly genetically correlated with the goal trait. This is beneficial for scarcely recorded traits, where phenotypes are not available on all individuals but routinely recorded traits are. Adding genotypic information to increase the accuracy of prediction for $\mathrm{CH}_{4}$ showed a significant advantage for the base single-trait scenario but not in the multitrait scenario. We conclude that the most feasible multitrait scenario in terms of feasibility when predicting $\mathrm{CH}_{4}$ for young candidates is the scenario with $\mathrm{CH}_{4}$, ECM, and BW information in the reference population. This scenario also proved to be the one most correlated with the base scenario.

\section{ACKNOWLEDGMENTS}

The work done in this paper was financed by the REFFICO project 34008-14-009 (Green Development and Demonstration Program, GUDP, Denmark) grants as well as the project "Beyond REMRUM," funded by the Danish Innovation Fund (Copenhagen, Denmark). The authors have not stated any conflicts of interest.

\section{REFERENCES}

Aguilar, I., I. Misztal, D. L. Johnson, A. Legarra, S. Tsuruta, and T. J. Lawlor. 2010. Hot topic: A unified approach to utilize phenotypic, full pedigree, and genomic information for genetic evaluation of Holstein final score. J. Dairy Sci. 93:743-752. https://doi.org/10 $.3168 /$ jds.2009-2730.

Aguilar, I., I. Misztal, S. Tsuruta, G. R. Wiggans, and T. J. Lawlor. 2011. Multiple trait genomic evaluation of conception rate in Holsteins. J. Dairy Sci. 94:2621-2624. https://doi.org/10.3168/jds .2010-3893.

Berry, D. P., F. Buckley, P. Dillon, R. D. Evans, M. Rath, and R. F. Veerkamp. 2003. Genetic parameters for body condition score, body weight, milk yield, and fertility estimated using random regression models. J. Dairy Sci. 86:3704-3717. https://doi.org/10 .3168/jds.S0022-0302(03)73976-9.

Breider, I. S., E. Wall, P. C. Garnsworthy, and J. E. Pryce. 2018. Genetic relationships between methane emission and milk yield, live weight and dry matter intake. 134 in Proceedings of the World Congress on Genetics Applied to Livestock Production, Volume Challenges-Environmental WCGALP, Auckland, New Zealand.

Buttchereit, N., E. Stamer, W. Junge, and G. Thaller. 2011. Genetic relationships among daily energy balance, feed intake, body condition score and fat to protein ratio of milk in dairy cows. J. Dairy Sci. 94:1586-1591. https://doi.org/10.3168/jds.2010-3396.

Calus, M. P., and R. F. Veerkamp. 2011. Accuracy of multi-trait genomic selection using different methods. Genet. Sel. Evol. 43:26. https://doi.org/10.1186/1297-9686-43-26.

Christensen, O. F., and M. S. Lund. 2010. Genomic prediction when some animals are not genotyped. Genet. Sel. Evol. 42:2. https:// doi.org/10.1186/1297-9686-42-2.

Daetwyler, H. D., R. Pong-Wong, B. Villanueva, and J. A. Woolliams. 2010. The impact of genetic architecture on genome-wide evaluation methods. Genetics 185:1021-1031. https://doi.org/10.1534/ genetics.110.116855.

de Haas, Y., J. J. Windig, M. P. L. Calus, J. Dijkstra, M. de Haan, A. Bannink, and R. F. Veerkamp. 2011. Genetic parameters for predicted methane production and potential for reducing enteric emissions through genomic selection. J. Dairy Sci. 94:6122-6134. https://doi.org/10.3168/jds.2011-4439.

Dechow, C. D., J. Vallimont, M. D. Dekleva, J. M. Daubert, and J. W. Blum. 2010. Genetic correlations of gross feed efficiency with yield, 
body weight, body condition score, and energy balance in dairy cattle. J. Dairy Sci. 93(E-Suppl. 1):184. (Abstr.)

Difford, G. F., J. Lassen, and P. Løvendahl. 2016. Interchangeability between methane measurements in dairy cows assessed by comparing precision and agreement of two non-invasive infrared methods. Comput. Electron. Agric. 124:220-226. https://doi.org/10.1016/j .compag.2016.04.010.

Difford, G. F., P. Løvendahl, R. F. Veerkamp, H. Bovenhuis, M. H. P. W. Visker, J. Lassen, and Y. de Haas. 2020. Can greenhouse gases in breath be used to genetically improve feed efficiency of dairy cows? J. Dairy Sci. 103:2442-2459. https://doi.org/10.3168/ jds.2019-16966.

Ducrocq, V. 1994. Multiple trait prediction: Principles and problems. Pages 7-12 in 5th World Congress on Genetics Applied to Livestock Production, Guelph, ON, Canada. Volume 18, pages 455462. University of Guelph, Guelph, ON, Canada.

Garnsworthy, P. C., J. Craigon, J. H. Hernandez-Medrano, and N. Saunders. 2012. Variation among individual dairy cows in methane measurements made on farm during milking. J. Dairy Sci. 95:3181-3189. https://doi.org/10.3168/jds.2011-4606.

Garnsworthy, P. C., G. F. Difford, M. J. Bell, A. R. Bayat, P. Huhtanen, B. Kuhla, J. Lassen, N. Peiren, M. Pszczola, D. Sorg, M. H. P. W. Visker, and T. Yan. 2019. Comparison of methods to measure methane for use in genetic evaluation of dairy cattle. Animals (Basel) 9:837. https://doi.org/10.3390/ani9100837.

Gebreyesus, G., M. S. Lund, L. Janss, N. A. Poulsen, L. B. Larsen, H. Bovenhuis, and A. J. Buitenhuis. 2016. Short communication: Multi-trait estimation of genetic parameters for milk protein composition in the Danish Holstein. J. Dairy Sci. 99:2863-2866. https: //doi.org/10.3168/jds.2015-10501.

Hayes, B. J., P. J. Bowman, A. J. Chamberlain, and M. E. Goddard. 2009. Invited review: Genomic selection in dairy cattle: Progress and challenges. J. Dairy Sci. 92:433-443. https://doi.org/10.3168/ jds.2008-1646.

Hayes, B. J., K. A. Donoghue, C. M. Reich, B. A. Mason, T. BirdGardiner, R. M. Herd, and P. F. Arthur. 2016. Genomic heritabilities and genomic estimated breeding values for methane traits in Angus cattle. J. Anim. Sci. 94:902-908. https://doi.org/10.2527/ jas.2015-0078.

Hayes, B. J., and M. E. Goddard. 2008. Technical note: Prediction of breeding values using marker-derived relationship matrices. J. Anim. Sci. 86:2089-2092. https://doi.org/10.2527/jas.2007-0733.

Hüttmann, H., E. Stamer, W. Junge, G. Thaller, and E. Kalm. 2009 Analysis of feed intake and energy balance of high-yielding first lactating Holstein cows with fixed and random regression models. Animal 3:181-188. https://doi.org/10.1017/S175173110800325X.

Interbull. 2018. National genetic evaluation forms provided by countries. Accessed Apr. 2, 2019. http://www.interbull.org/ib/geforms.

Jia, Y., and J.-L. Jannink. 2012. Multiple-trait genomic selection methods increase genetic value prediction accuracy. Genetics 192:1513-1522. https://doi.org/10.1534/genetics.112.144246.

Knapp, J. R., G. L. Laur, P. A. Vadas, W. P. Weiss, and J. M. Tricarico. 2014. Invited review: Enteric methane in dairy cattle production: Quantifying the opportunities and impact of reducing emissions. J. Dairy Sci. 97:3231-3261. https://doi.org/10.3168/jds 2013-7234.

Lassen, J., and P. Løvendahl. 2016. Heritability estimates for enteric methane emissions from Holstein cattle measured using noninvasive methods. J. Dairy Sci. 99:1959-1967. https://doi.org/10 .3168/jds.2015-10012.

Lassen, J., P. Løvendahl, and J. Madsen. 2012. Accuracy of noninvasive breath methane measurements using Fourier transform infrared methods on individual cows. J. Dairy Sci. 95:890-898. https:/ /doi.org/10.3168/jds.2011-4544.

Li, B., B. Berglund, W. F. Fikse, J. Lassen, M. H. Lidauer, P. Mäntysaari, and P. Løvendahl. 2017. Neglect of lactation stage leads to naïve assessment of residual feed intake in dairy cattle. J. Dairy Sci. 100:9076-9084. https://doi.org/10.3168/jds.2017-12775.

Li, B., W. Fikse, P. Løvendahl, J. Lassen, M. H. Lidauer, P. Mäntysaari, and B. Berglund. 2018. Genetic heterogeneity of feed in- take, energy-corrected milk, and body weight across lactation in primiparous Holstein, Nordic Red, and Jersey cows. J. Dairy Sci. 101:10011-10021. https://doi.org/10.3168/jds.2018-14611.

Madsen, J., B. S. Bjerg, T. Hvelplund, M. R. Weisbjerg, and P. Lund. 2010. Methane and carbon dioxide ratio in excreted air for quantification of the methane production from ruminants. Livest. Sci. 129:223-227. https://doi.org/10.1016/j.livsci.2010.01.001.

Madsen, P., and J. Jensen. 2014. A User's Guide to DMU, Version 6, Release 5.0. Center for Quantitative Genetics and Genomics, Department of Molecular Biology and Genetics, Aarhus University, Tjele Denmark.

Manzanilla-Pech, C. I. V., R. F. Veerkamp, M. P. L. Calus, R. Zom, A. van Knegsel, J. E. Pryce, and Y. De Haas. 2014. Genetic parameters across lactation for feed intake, fat- and protein-corrected milk, and liveweight in first-parity Holstein cattle. J. Dairy Sci. 97:5851-5862. https://doi.org/10.3168/jds.2014-8165.

Mrode, R. A. 2013. Linear Models for the Prediction of Animal Breeding Values. 3rd ed. CABI, Oxfordshire, UK.

Muller, C. J. C., S. W. P. Cloete, J. J. Olivier, J. A. Botha, and H. de Waal. 2006. Heritability of live weight and condition score in a Holstein herd and correlations with milk traits - Preliminary estimates. S. Afr. J. Anim. Sci. 36:79-88. https://doi.org/10.4314/ sajas.v36i2.3989.

Pszczola, M., K. Rzewuska, S. Mucha, and T. Strabel. 2017. Heritability of methane emissions from dairy cows over a lactation measured on commercial farms. J. Anim. Sci. 95:4813-4819. https: //doi.org/10.2527/jas2017.1842.

Pszczola, M., R. F. Veerkamp, Y. de Haas, E. Wall, T. Strabel, and M. P. Calus. 2013. Effect of predictor traits on accuracy of genomic breeding values for feed intake based on a limited cow reference population. Animal 7:1759-1768. https://doi.org/10.1017/ S175173111300150X.

Purcell, S., B. Neale, K. Todd-Brown, L. Thomas, M. A. R. Ferreira, D. Bender, J. Maller, P. Sklar, P. I. W. De Bakker, M. J. Daly, and P. C. Sham. 2007. PLINK: A tool set for whole-genome association and population-based linkage analyses. Am. J. Hum. Genet. 81:559-575. https://doi.org/10.1086/519795.

Ross, E. M., P. J. Moate, L. Marett, B. G. Cocks, and B. J. Hayes. 2013. Investigating the effect of two methane-mitigating diets on the rumen microbiome using massively parallel sequencing. J. Dairy Sci. 96:6030-6046. https://doi.org/10.3168/jds.2013-6766.

Sargolzaei, M., J. P. Chesnais, and F. S. Schenkel. 2014. A new approach for efficient genotype imputation using information from relatives. BMC Genomics 15:478. https://doi.org/10.1186/1471 $-2164-15-478$.

Sjaunja, L. O., L. Baevre, L. Junkkarinen, J. Pedersen, and J. Setala. 1990. A Nordic Proposal for and Energy Corrected Milk (ECM) Formula. EAAP Publication 50, Centre for Agricultural Publishing and Documentation, Wageningen, the Netherlands.

Song, H., J. Zhang, Q. Zhang, and X. Ding. 2019. Using different single-step strategies to improve the efficiency of genomic prediction on body measurement traits in pig. Front. Genet. 9:730. https: //doi.org/10.3389/fgene.2018.00730.

Thompson, R., and K. Meyer. 1986. A review of theoretical aspects in the estimation of breeding values for multi-trait selection. Livest. Prod. Sci. 15:299-313. https://doi.org/10.1016/0301 -6226(86)90071-0.

Tsuruta, S., I. Misztal, I. Aguilar, and T. J. Lawlor. 2011. Multiple-trait genomic evaluation of linear type traits using genomic and phenotypic data in US Holsteins. J. Dairy Sci. 94:4198-4204. https://doi.org/10.3168/jds.2011-4256.

van Engelen, S., H. Bovenhuis, J. Dijkstra, J. A. M. van Arendonk, and M. H. P. W. Visker. 2015. Short communication: Genetic study of methane production predicted from milk fat composition in dairy cows. J. Dairy Sci. 98:8223-8226. https://doi.org/10 $.3168 /$ jds.2014-8989.

van Engelen, S., H. Bovenhuis, P. P. J. van der Tol, and M. H. P. W. Visker. 2018. Genetic background of methane emission by Dutch Holstein Friesian cows measured with infrared sensors in auto- 
matic milking systems. J. Dairy Sci. 101:2226-2234. https://doi .org/10.3168/jds.2017-13441.

VanRaden, P. M. 2008. Efficient methods to compute genomic predictions. J. Dairy Sci. 91:4414-4423. https://doi.org/10.3168/jds 2007-0980

VanRaden, P. M., C. P. Van Tassell, G. R. Wiggans, T. S. Sonstegard, R. D. Schnabel, J. F. Taylor, and F. S. Schenkel. 2009. Invited review: Reliability of genomic predictions for North American Holstein bulls. J. Dairy Sci. 92:16-24. https://doi.org/10.3168/jds $.2008-1514$
Waghorn, G. C., and R. S. Hegarty. 2011. Lowering ruminant methane emissions through improved feed conversion efficiency. Anim. Feed Sci. Technol. 166-167:291-301. https://doi.org/10.1016/j .anifeedsci.2011.04.019.

Zetouni, L., M. Kargo, E. Norberg, and J. Lassen. 2018. Genetic correlations between methane production and fertility, health, and body type traits in Danish Holstein cows. J. Dairy Sci. 101:2273-2280. https://doi.org/10.3168/jds.2017-13402. 